\title{
Comparison between SWAT and SWAT+ for simulating streamflow in a paddy-field- dominated basin, northeast Thailand
}

\author{
Isared Kakarndee ${ }^{1}$, and Ekasit Kositsakulchai $^{{ }^{*}}$ \\ ${ }^{1}$ Kasetsart University, Department of Irrigation Engineering, Nakhon Pathom, 73140, Thailand
}

\begin{abstract}
The performance of the well-known Soil and Water Assessment Tool (SWAT) and the new SWAT+ for streamflow simulation in a paddyfield-dominated basin was compared. The Lam Sioa River Basin, northeast Thailand (drainage area of $3,394 \mathrm{~km}^{2}$ ) was selected. The data inputs consisted of DEM, land use, soil, and climate (rainfall, temperature, sunshine hour, wind speed and humidity). The model parameters used the default values from SWAT database and daily simulation was conducted from 2005 to 2017. The division of sub-basins into "landscape units" is one of new features of SWAT+. The total number of HRUs defined from SWAT+ were higher than those from SWAT because the sub-basins derived from SWAT+ contained two landscape units (floodplain and upslope). With the default model parameters, the model performance indicators were found below the satisfactory rating. Both models simulated relatively high streamflow at the beginning of rainy season, while the observed streamflow was still not occurred. In paddy field, rainfall excess become ponding water, not surface runoff. The appropriate representation of paddy field in SWAT model should be further investigated.
\end{abstract}

\section{Introduction}

The Soil and Water Assessment Tool (SWAT) has become widely applied across the globe more than 20 years ago [1]. Gassman et al [2] reviewed the development history of SWAT model including GIS interface tools and examples of modified version of SWAT, the summary of research findings or methods, the description of modeling strengths and weaknesses, and a list of future research needs. In Thailand, SWAT models have been widely used for hydrological studies because the modeling approach is capable to simulate results at reduced cost before decision-making. The examples of SWAT application in Thailand are as follows: hydrological evaluation in the Mun River Basin [3], hydrological simulation using the global land use in the Upper Yom River Basin [4], assessment of land-use change impacts on discharge and water quality in an agricultural land [5], evaluation of the sediment and nutrient loads in Lam Takong River Basin [6], and estimation of runoff due to the changes from climate and land use in Lower Lampao River Basin [7].

*Corresponding author: ekasit.k@ku.th 
Although SWAT model was applied under the varieties of hydrological condition, some limitations particularly in lowland were reported. The SWAT+ was further developed to enhance the model performance. It is a new restructured version of SWAT with improved runoff routing capabilities [8] with the GIS interface written in the Python which uses the QGIS functions, and continuously developed for including the flexible spatial representation of interactions and processes within a watershed [9]. A comparative study [10] reported that no serious setback in the passage from the previous SWAT to the new SWAT+ in the accuracy of the hydrologic simulation.

The comparative study evaluated the performance of the new SWAT+ model for streamflow simulation by comparing the simulated results using the default parameters with those from the previous SWAT. The study focused on the improvement of the model for streamflow simulation in a paddy-field-dominated basin, in the northeast Thailand.

\section{Materials and methods}

\subsection{Study area}

The Lam Siao Basin is a sub-basin of the Mun River Basin, Northeast Thailand (Figure 1). The basin has a drainage area of $3,394.81 \mathrm{~km}^{2}$ ranging from latitude $15^{\circ} 20^{\prime}$ to $16^{\circ} 10^{\prime} \mathrm{N}$ and longtitude $103^{\circ} 00^{\prime}$ to $103^{\circ} 60^{\prime} \mathrm{E}$. It is located in Roi Et and Maha Sarakham provinces. The main stream of the basin is $94.67 \mathrm{~km}$ length which has the Lam Siao Yai River flowing from the Maha Sarakam province to join with the Lam Siao River as the main river at Suvarnabhumi District, Roi Et Province. The topography of the basin is a plateau that slopes eastward along the river. The altitude varies from 118 meter above sea level (m asl.) at the river outlet until $195 \mathrm{~m}$ a.s.l at the M.95 station gage. The climate in the Basin is influenced by the southwest monsoon from May to October and the tropical cyclones from the South China Sea from September to October (at the end of rainy season) [11]. The total annual rainfall was 1,100-1,400 mm. Temperature in April (the hottest month) reaches an average maximum temperature of $38^{\circ} \mathrm{C}$, while in January (the coldest) has an average minimum temperature of $18^{\circ} \mathrm{C}$ (Figure 1). Land use in the basin was dominantly characterized by paddy field $(80 \%)$. Soil textures in the upstream area to the central part of the basin are sandy clay loam and loamy sand. In the lower downstream soil textures are sandy clay or sandy clay loam.

\subsection{Model description}

The Soil and Water Assessment Tool Plus (SWAT+) is a completely restructured version of the SWAT. QSWAT+, the QGIS interface for SWAT+, was developed using Python and used various QGIS functionalities. The website for download is https://swat.tamu.edu/software/plus/. SWAT+ provides a more flexible spatial representation of interactions and processes within a watershed [12], in a small watershed to river basinscale model to simulate the quality and quantity of surface and ground water and predict the environmental impact of land use, land management practices, and climate change [13]. The current interface performs similar functions to SWAT [13].The first one is the land phase where the hydrologic cycle in a basin is simulated based on the water balance equation. (Equation 1) 

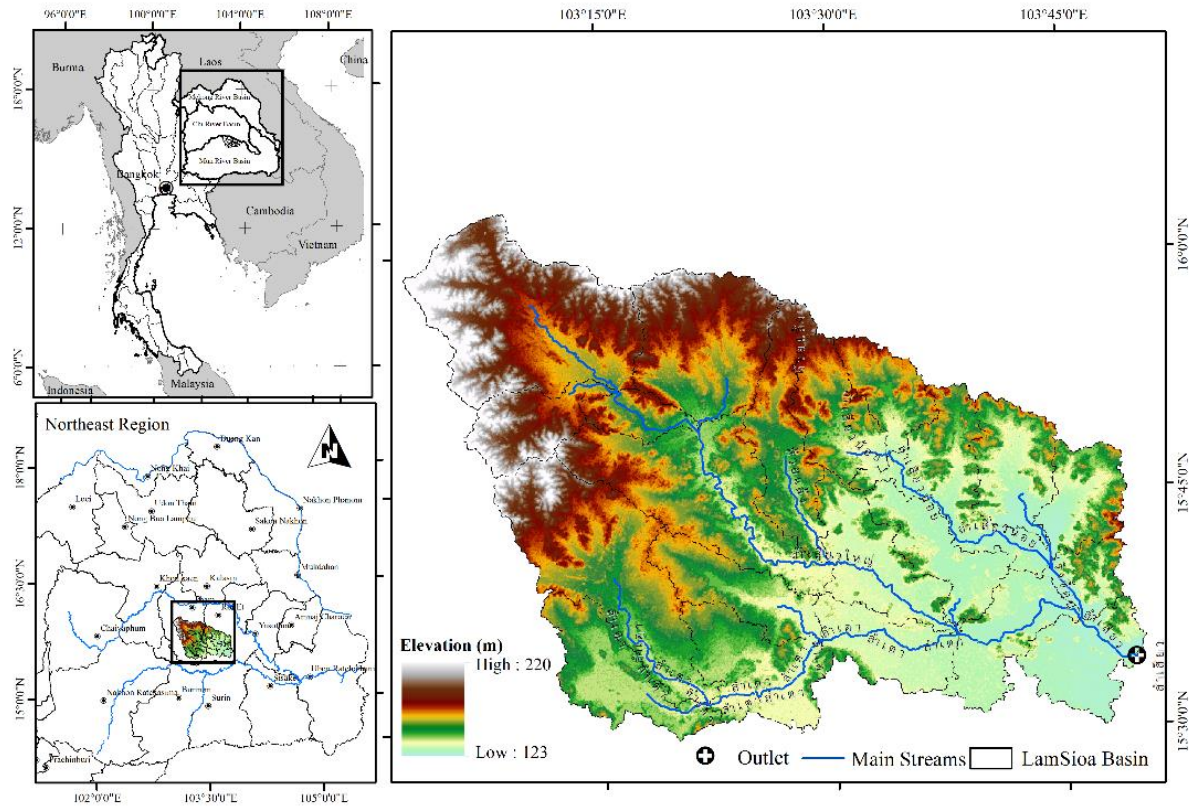

Fig. 1. Study area (Lam Sioa Basin).

$$
S W_{t}=S W_{0}+\sum_{i=1}^{t}\left(R_{d a y}-Q_{\text {surf }}-E T_{\text {day }}-W_{d a y}-Q_{g w}\right)
$$

where $S W_{t}$ is the soil water content (mm), $S W_{0}$ is the initial soil water content on day $i(\mathrm{~mm})$, $t$ is the time (day), $R_{\text {day }}$ is the precipitation on day $i(\mathrm{~mm}), Q_{\text {surf }}$ is the surface runoff on day $i$ $(\mathrm{mm}), E T_{\text {day }}$ is the evapotranspiration on day $i(\mathrm{~mm}), W_{\text {day }}$ is the water entering the unsaturated zone from the soil profile on day $i(\mathrm{~mm})$, and $Q_{g w}$ is the amount of return flow on day $i(\mathrm{~mm})$.

The surface runoff is estimated using the NRCS Curve Number (CN) method (Equation 2):

$$
Q_{\text {surf }}=\frac{\left(R_{d a y}-I_{a}\right)^{2}}{R_{d a y}-I_{a}-S}, R_{d a y}>I_{a}
$$

where $Q_{\text {surf }}$ is the surface runoff or rainfall excess (mm), $R_{\text {day }}$ is the rainfall depth for the day $(\mathrm{mm}), I_{a}$ is the initial abstraction (surface storage, interception, and infiltration prior to runoff) $(\mathrm{mm}), S$ is the retention parameter $(\mathrm{mm})$. The retention parameter depends on topography (slope), soil, land use, management practices (Equation 3), and changes with the time due to soil water content:

$$
S=25.4(1000 / C N-10)
$$


where $C N$ is the NRCS curve number corresponding to antecedent water content, soil infiltration, land use and land management conditions [14].

\subsection{Model performance evaluation}

The model performance for streamflow simulation, a quantitative general performance rating, was formulated [15] using the percentage bias (PBIAS) in Equation 4, the coefficient of determination $\left(\mathrm{R}^{2}\right)$ in Equation 5, and the Nash-Sutcliffe efficiency (NSE) [16] in Equation 6. The NSE is a normalized statistic that determines the relative magnitude of the residual variance compared to the measured data variance.

$$
\begin{gathered}
\text { PBIAS }=\left(\frac{\sum_{i=1}^{n} O_{i}-\sum_{i=1}^{n} P_{i}}{\sum_{i=1}^{n} O_{i}}\right) \times 100 \\
\mathrm{R}^{2}=\left(\frac{\sum_{i=1}^{n}\left(O_{i}-\bar{O}\right)\left(P_{i}-\bar{P}\right)}{\sqrt{\sum_{i=1}^{n}\left(O_{i}-\bar{O}\right)^{2}} \sqrt{\sum_{i=1}^{n}\left(P_{i}-\bar{P}\right)^{2}}}\right)^{2} \\
\mathrm{NSE}=1-\frac{\sum_{i=1}^{n}\left(O_{i}-P_{i}\right)^{2}}{\sum_{i=1}^{n}\left(O_{i}-\bar{O}_{i}\right)^{2}}
\end{gathered}
$$

With $P_{i}$ and $O_{i}$ are respectively the simulated and observed streamflow at time step $\left(\mathrm{m}^{3} / \mathrm{s}\right)$, $\bar{P}$ and $\bar{O}$ are the corresponding means of the simulated and observed streamflow over the entire period $\left(\mathrm{m}^{3} / \mathrm{s}\right)$, and $n$ is the total number of streamflow data points.

\subsection{Data used}

The spatial data used in SWAT model for the study including a DEM with resolution 90 meters, was obtained from http://srtm.csi.cgiar.org/. These data were used to delineate the watershed boundary, to define the drainage patterns, to calculate slopes of the study area and channels, and to create HRUs. Soil and land use maps were obtained from the Land Development Department (LDD) (Figure 2). For some soil groups without the required properties (e.g. slope complex [SC]), the soil-landscape evaluation approach was applied for estimating the missing soil properties [17]. The daily climatic data were required for simulating hydrological processes in the watershed. The data acquiredfrom the Thai Meteorological Department (TMD) included relative humidity, temperatures (maximum and minimum), solar radiation (sunshine hours), air humidity (relative humidity), and wind speed. The guaged discharges from 2005 to 2017 obtained from the Royal Irrigation Department (RID) are the observed data for evaluating the results of model. 

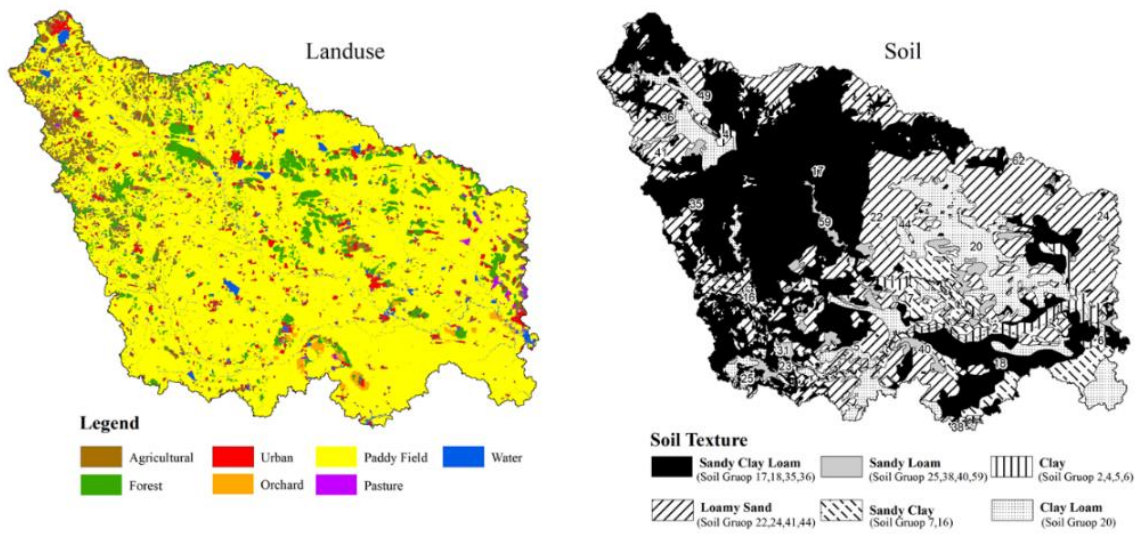

Fig. 2. Land use and soil maps of the Lam Sioa Basin.

\subsection{Methodology}

The SWAT+ has a modeling interface using QGIS plug-in and uses the SQLite database for data management. While the SWAT has an interface using ArcGIS extension and use Microsoft Access for database management. The modeling steps using SWAT and SWAT+ are rather similar. In this study, we reserved all default values in the SWAT database for model's parameter setting.

The first step was the watershed delineation. The basin was modeled using the topographical data and other inputs (e.g., the spatial location of the basin outlet) and defined the boundaries of the basin and subdivided into sub-basins. The outlet basin was manually added corresponding to locations in the watershed where streamflow data were routinely measured.

In the second step, the Dominant HRUs option in SWAT models was selected for creating further subdivide each sub-basin into Hydrologic Response Units (HRUs). The division of sub-basins into "landscape units" (floodplain and upslope) is one of new feature of SWAT+. There are three options for creating landscape units: the buffer streams method, the DEM inversion method, and the branch length method. The first method, "buffer streams", make the floodplain simply as a buffer drawn around the stream reaches. There is no terrain analysis involved. The second method is called "DEM inversion". It is calculated by negating all the DEM elevations and recalculating flow directions, and calculating how much water would then flow into each point, the flow accumulation. The third method of creating landscape units is the "branch length" method. This method uses the same slope position as the previous method, but the different ridge-definition method.

The final step included the compiling of climatic data and writing as the preliminary of SWAT inputs files. For the SWAT+ setting of time period and simulation options was done in the SWAT+ Editor. The warm-up period was 2 years and simulation period from January 2003 to June 2017. Finally, after running models outputs were summarized and exported on monthly basis.

\section{Results and discussion}

One of new feature of SWAT + is the possibility to divide sub-basins into "landscape units"floodplain and upslope. The floodplain area of the Lam Sioa Basin derived from the buffering streams method was $435.86 \mathrm{~km}^{2}$ (Figure 3a), the DEM inversion method (Figure 3b), 781.15 
$\mathrm{km}^{2}$; and the branch length method, $651.38 \mathrm{~km}^{2}$ (Figure $3 \mathrm{c}$ ). The buffering streams method resulted in unrealistic floodplain, while the DEM inversion and the branch length methods seemed more convincing. The DEM inversion method was finally selected for the study due to the extents of the derived floodplain close to the flood prone area in the basin.

After having defined the landscape units, the HRUs were later defined within each landscape unit. The total number of sub-basins between SWAT and SWAT+ were equal, but the total number of HRUs of SWAT+ (293 units) were higher than those of SWAT (22 units). The sub-basins in SWAT+ contained two landscape units (floodplain and upslope), thus the greater number of HRUs was defined. The majority of HRUs retain the following properties: paddy filed, sandy clay loam soil, and less than $3 \%$ of slope. Although, the number of HRUs from both models were different, the total drainage areas of basin were identical. Both models defined watershed area approximately $3,390 \mathrm{~km}^{2}$ (Figure 4).

The means of annual water balance components between SWAT and SWAT+ were compared in Table 1. The mean annual rainfall resulted from both models was approximately $1,390 \mathrm{~mm}$, while the mean annual evapotranspiration from SWAT+ $(792 \mathrm{~mm})$ was $270 \mathrm{~mm}$ higher than that from SWAT $(519 \mathrm{~mm})$. SWAT+ provided relatively low percolation into aquifer SWAT+ $(34.90 \mathrm{~mm})$ comparing to SWAT $(287.47 \mathrm{~mm})$. The average water yield of the sub-basins from SWAT and SWAT+ were respectively $840.64 \mathrm{~mm}$ and $535.75 \mathrm{~mm}$. The simulated components of water balance at basin level were significantly different, however both models were set up using default parameters. The further calibration could improve the results, hence decrease the difference.

Figure 5 shows the comparison of monthly streamflow from 2005 to 2017 at the M.95 gage station. The observations were shown in the bold black line, the SWAT + simulation in the dash red line, and the SWAT simulation in the dash black line. With the default model parameters, both models simulated relatively high streamflow during the beginning of rainy season, while the observed streamflow was still not occurred during that period. The performance indicators were found below the satisfactory rating (NSE $\leq 0.50,|\mathrm{PBIAS}| \geq 15$, and R2 $\leq 0.50$ [15]). Some calibration using SWAT-CUP [18] have been conducted without success. The majority of the Lam Sioa Basin was the rain-fed agricultural land. The land was dominated by paddy field with fairly high bund, in addition natural/man-made water storages (small ponds) spread over the basin. Subsequently, when rainfall excess occurs during the beginning of rainy season, it is kept in the paddy field or refill the pond not becomes surface runoff to stream. The representation of water processes in paddy field of SWAT+ seems not superior to that in SWAT. The appropriate representation of paddy field should be further investigated [19-22].

\section{Conclusions}

This study evaluated the performance of the new SWAT+ model for streamflow simulation in the Lam Sioa Basin, Northeast Thailand. The total number of HRUs defined from SWAT+ were higher than those from SWAT because the sub-basins derived from SWAT+ contained two landscape units (floodplain and upslope). With the default model parameters, both models simulated relatively high streamflow at the beginning of rainy season, while the observed streamflow was still not occurred. In paddy field, rainfall excess become ponding water, not surface runoff. The representation of paddy field in SWAT model should be investigated in the future studies. 
Table 1. Water balance components simulated by SWAT and SWAT + in the Lam Sioa Basin.

\begin{tabular}{|c|r|r|r|}
\hline $\begin{array}{c}\text { Water balance } \\
\text { components }(\mathbf{m m})\end{array}$ & \multicolumn{1}{c|}{ SWAT } & \multicolumn{1}{c|}{ SWAT+ } & \multicolumn{1}{c|}{ Difference } \\
\hline Precipitation & $1,386.40$ & $1,398.51$ & +12.11 \\
\hline Evapotranspiration & 519.26 & 791.77 & +272.51 \\
\hline Percolation & 287.47 & 34.90 & -252.57 \\
\hline Water yield & 840.64 & 535.75 & -304.89 \\
- Surface runoff & 577.70 & 529.72 & -47.98 \\
- Lateral flow & 0.25 & 6.05 & +5.80 \\
- Groundwater flow & 14.50 & 31.62 & +17.12 \\
\hline
\end{tabular}
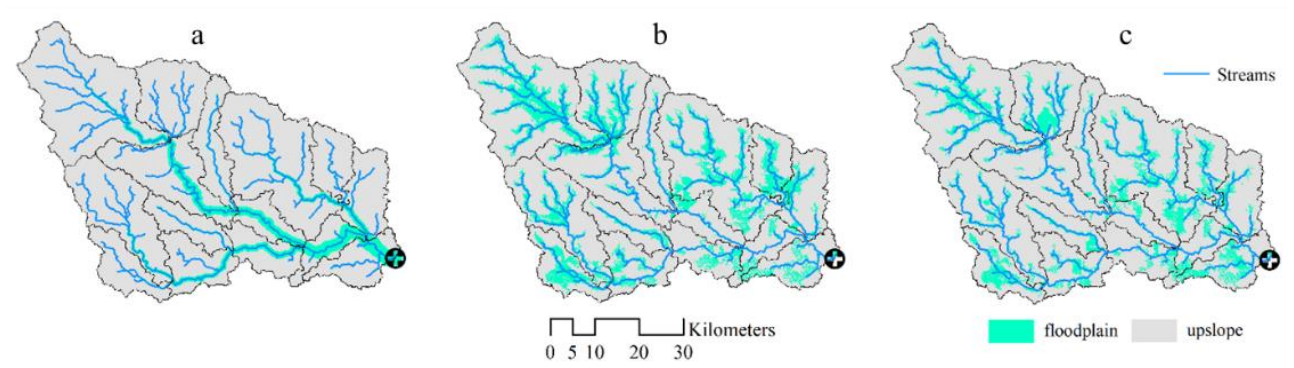

Fig. 3. Comparison of landscape units using three options available from the QSWAT+:

(a) Buffer streams method, (b) DEM inversion method, and (c) Branch length method.
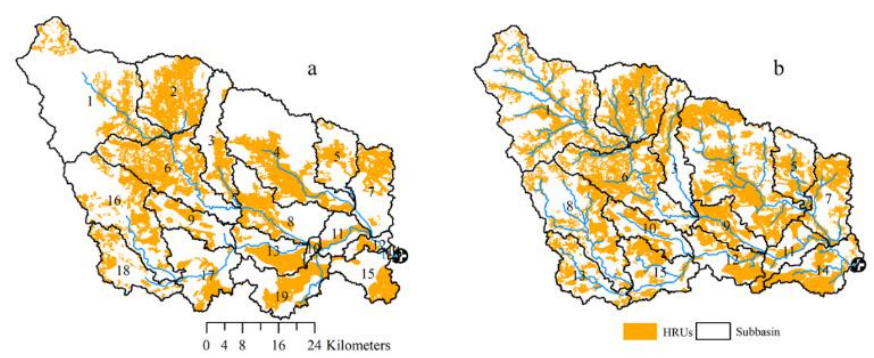

Fig. 4. Comparison of sub-basins defined by (a) SWAT model and (b) SWAT + model.

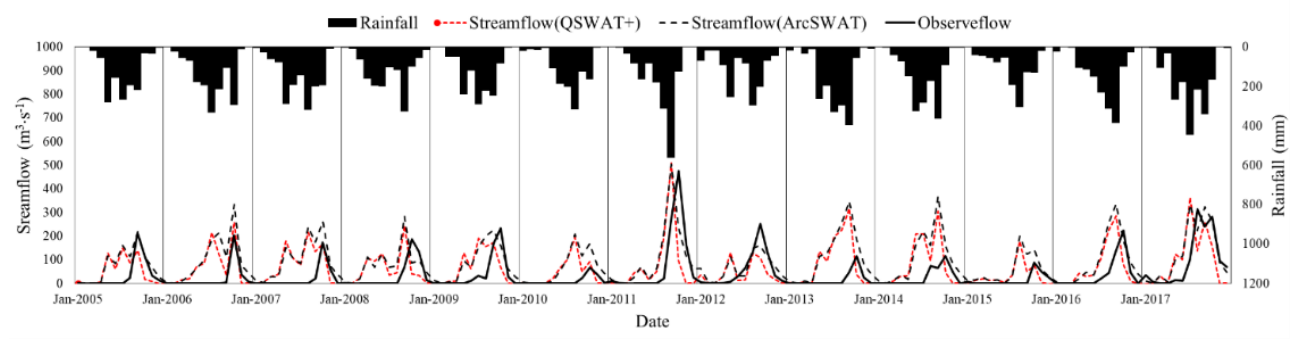

Fig. 5. Monthly streamflow (January 2005 to December 2017). 
Acknowledgements: This research was supported by grants from the Faculty of Engineering at Kamphaeng Saen and the Graduate School, Kasetsart University, Thailand. The authors would also like to express their gratitude to developers of the SWAT and SWAT+ models for granting the licenses for this research.

\section{References}

1. J. R. Williams, J. G. Arnold, J. R. Kiniry, P. W. Gassman and C. H. Green, Hydrol. Sci. J. 53 (5), 948-960 (2008).

2. P. Gassman, M. Reyes, C. Green and J. Arnold, Transac. ASABE 50 (2007).

3. A. Akter and M. S. Babel, J. Hydrol. 452, 232-246 (2012).

4. C. Chirachawala, S. Shrestha, M. S. Babel, S. G. P. Virdis and S. Wichakul, Sci. Total Environ. 708, 135-148 (2020).

5. S. Chotpantarat and S. Boonkaewwan, Hydrol. Sci. J. 63 (9), 1386-1407 (2018).

6. N. Pongpetch, P. Suwanwaree, C. Yossapol, S. Dasananda and K. Thongplew, Environmentasia 8 (1), 41-52 (2015).

7. H. Prasanchum, A. Kangrang, R. Hormwichian and S. Compliew, Mahasarakham International Journal of Engineering Technology 2 (2), 1-5 (2016).

8. K. Bieger, J. G. Arnold, H. Rathjens, M. J. White, D. D. Bosch and P. M. Allen, J. Am. Water Resour. Assoc. (2019).

9. K. Bieger, J. G. Arnold, H. Rathjens, M. J. White, D. D. Bosch, P. M. Allen, M. Volk and R. Srinivasan, J. Am. Water Resour. Assoc. 53 (1), 115-130 (2017).

10. Y. Her and J. Jeong, T. ASABE. 61 (4), 1287-1295 (2018).

11. E. Biltonen, B. Kwanyuen, E. Kositsakulchai and S. Pattani, in Governance for Integrated Water-Resources Management in a River-Basin Context, edited by B. Bruns and D. J. Bandaragoda (International Water Management Institute (IWMI), Colombo, 2003), pp. 109-137.

12. K. Bieger, J. G. Arnold, H. Rathjens, M. J. White, D. D. Bosch, P. M. Allen, M. Volk and R. Srinivasan, J. Am. Water Resour. Assoc. 53 (1), 115-130 (2017).

13. Y. T. Dile, P. Daggupati, C. George, R. Srinivasan and J. Arnold, Environ. Model. Softw. 85, 129-138 (2016).

14. K. X. Soulis and J. D. Valiantzas, Hydrol. Earth Syst. Sci. 16 (3), 1001-1015 (2012).

15. D. N. Moriasi, J. G. Arnold, M. W. Van Liew, R. L. Bingner, R. D. Harmel and T. L. Veith, T. ASABE. 50 (3), 885-900 (2007).

16. J. E. Nash and J. V. Sutcliffe, J. Hydrol. 10 (3), 282-290 (1970).

17. I. Kakarndee and E. Kositsakulchai, Appl. Environ. Res. 41 (3), 1-13 (2019).

18. K. C. Abbaspour, SWAT-CUP: SWAT Calibration and Uncertainty Programs - A User Manual. (Swiss Federal Institute of Aquatic Science and Technology (Eawag), 2015).

19. X. Xie and Y. Cui, J. Hydrol. 396 (1), 61-71 (2011). 
20. A. Sakaguchi, S. Eguchi and M. Kasuya, Soil Sci. Plant Nutr. 60 (4), $551-564$ (2014).

21. A. Sakaguchi, S. Eguchi, T. Kato, M. Kasuya, K. Ono, A. Miyata and N. Tase, Agric. Water Manag. 137, 116-122 (2014).

22. R. Tsuchiya, T. Kato, J. Jeong and J. G. Arnold, Sustainability 10 (9), 3246 (2018). 